\title{
Investigation of Susceptibility to Intergranular Corrosion of Tin-Added Austenitic Stainless Steel
}

\author{
Min Sun ${ }^{1,2} \cdot$ Yuan-Yuan Yang ${ }^{1} \cdot$ Ming Luo $^{2} \cdot$ Lai-Zhu Jiang $^{2} \cdot$ Yi-Ming Jiang ${ }^{1} \cdot$ Jin Li $^{1}$
}

Received: 1 May 2015/Revised: 1 August 2015/Published online: 8 September 2015

(C) The Chinese Society for Metals and Springer-Verlag Berlin Heidelberg 2015

\begin{abstract}
The intergranular corrosion (IGC) character of tin-added B316LX and the influence of tin addition on IGC susceptibility were investigated by DL-EPR, oxalic acid etch test and transmission electron microscopy. IGC susceptibility of $\mathrm{B} 316 \mathrm{LX}$ is mainly caused by the precipitation of $M_{23} \mathrm{C}_{6}$ carbide and intermetallic Laves phase. DL-EPR test is unsuitable to evaluate the IGC susceptibility of B316LX with long-time sensitization, because more carbides and intermetallic phases are formed at grain boundaries and inside the grains, which induce more severe IGC and pits attacks. Tin addition increases the IGC susceptibility, maybe due to diffusion of tin toward grain boundaries.
\end{abstract}

KEY WORDS: Stainless steel; Tin; SEM; TEM; Intergranular corrosion

\section{Introduction}

Austenitic stainless steels (ASS) are largely used in construction industries due to their good combination of mechanical, fabrication as well as corrosion resistance properties in very aggressive environment [1-4]. High alloying content, such as chromium, nickel and molybdenum, is the reason of good corrosion resistance. However, chromium and nickel are rather pricey, and the price change of raw materials greatly influences the cost of stainless steels. Therefore, their replacement using small amounts of other alloying elements, such as nitrogen and manganese, is commonplace. As a trace element, tin has been added to ASSs. The use of tin addition can be justified

Available online at http://link.springer.com/journal/40195

Jin Li

corrosion@fudan.edu.cn

1 Department of Materials Science, Fudan University, Shanghai 200433, China

2 Research and Development Center, Baosteel Co., Ltd., Shanghai 201900, China as follows: (a) tin increases general corrosion resistance; (b) it improves the formability and surface finish with fewer ridging pattern; (c) modest addition of tin conserves alloy resources by replacing partially chromium and nickel and is stable in cost by minimizing the effect of fluctuations of raw material prices [5].

Sensitization of ASSs results from chromium carbides precipitation, which creates chromium depletion zones adjacent to the grain boundaries [6]. As result, the chromium-depleted zones become anodic and are corroded in an aggressive environment [7-10]. Sensitization may be also consequence of intermetallic $\mathrm{Cr}$-rich phases precipitated in ASSs and duplex stainless steels [11].

There are several typical tests to detect IGC sensitization of stainless steels qualitatively as follows. The samples are electrolytically etched in oxalic acid solution as per ASTM standard A262 practice A. The etched surface is examined and characterized as step, dual or ditch structure. Further all the bend samples are tested in $\mathrm{CuSO}_{4}-\mathrm{H}_{2} \mathrm{SO}_{4}-$ $\mathrm{Cu}$ solution as per ASTM standard A262 practice E. If cracks are found after the test it is concluded that the samples are sensitized and hence susceptible to IGC. However, these two tests are only qualitative but not quantify the extent of IGC. The requirement for a simple, 
non-destructive and quantitative approach to determine the IGC sensitization of stainless steels led to the development of the double loop electrochemical potentiokinetic reactivation (DL-EPR) test method. DL-EPR test is a rapid test method, which is essentially suitable for field use.

So far, some researchers have studied that the beneficial effect of tin addition on ASSs corrosion in acid mediums and showed the positive effect of the interaction of tin with $\mathrm{Cu}$ and $\mathrm{Sb}$ improved the formation of a continuous, adherent rust layer [12-15]. However, all of the studies are focusing on the effects of tin addition on general corrosion and pitting behavior of tin-added ASS in a sulfuric acid chloride containing environment.

To data, no report has been found to study the IGC behavior of tin-added ASS. Therefore, in this work, tinadded ASS based on 316L was investigated by DL-EPR test and oxalic acid etch test. Optical microscopic structures and SEM were inspected after sensitization treatment and IGC tests.

\section{Experimental Procedures}

\subsection{Material and Heat Treatment}

Tin-added ASS was used as experimental material from Baosteel Research Institute, with $0.08 \mathrm{wt} \%$ tin at the base of $316 \mathrm{~L}$ stainless steel. The chemical composition (in $\mathrm{wt} \%$ ) of tin-added ASS is $0.0188 \mathrm{C}, 0.5 \mathrm{Si}, 1.43 \mathrm{Mn}, 0.002 \mathrm{~S}$, $0.024 \mathrm{P}, 16.14 \mathrm{Cr}, 10.27 \mathrm{Ni}, 0.15 \mathrm{Cu}, 2.01 \mathrm{Mo}, 0.0265 \mathrm{~N}$, $0.08 \mathrm{Sn}$ and balanced of $\mathrm{Fe}$. The experimental samples were cut into $10 \mathrm{~mm} \times 10 \mathrm{~mm}$ from a sheet after cold rolling with a thickness of $0.5 \mathrm{~mm}$. All the samples were solution treated at $1120{ }^{\circ} \mathrm{C}$ for $2 \mathrm{~h}$ in $\mathrm{N}_{2}$ flow then waterquenched to homogenize and prevent the precipitation of second phases in the steels. After that the samples were heat treated to obtain the temperature-time-sensitization (TTS) curves and produce microstructural changes that can influence IGC susceptibility. The temperatures and time were chosen to fit the range of likely chromium-rich carbide precipitation, which is $600,650,700,750$ and $800{ }^{\circ} \mathrm{C}$ for $0.5-100 \mathrm{~h}$, respectively. After heat treatments, samples were ground to 2000 grit $\mathrm{SiC}$ paper with water as lubricant to remove the oxide layer on the material surface, then cleaned with alcohol and dried with cold air.

\subsection{DL-EPR Test}

The electrochemical measurements were carried out with a PARSTAT 2273 electrochemical system, using a conventional three-electrode cell. The aged tin-added ASSs were used as the working electrodes, which were embedded in epoxy resin leaving a working area of $10 \mathrm{~mm} \times 10 \mathrm{~mm}$.
All samples were polished and cleaned by ethanol and deionized water prior to tests. A platinum sheet was used as the counter electrode, and a saturated calomel electrode (SCE) as the reference electrode connected to the cell via a Luggin probe.

DL-EPR test is a non-destructive method to evaluate the IGC property of material. The solution of $0.5 \mathrm{~mol} / \mathrm{L} \mathrm{H}_{2}$ $\mathrm{SO}_{4}+0.01 \mathrm{~mol} / \mathrm{L} \mathrm{KSCN}$ was chosen as the test solution according to ASTM G108-2004 [16]. The working electrode was cathodically polarized at $-900 \mathrm{mV}_{\mathrm{vs} . \mathrm{SCE}}$ for 2 min to remove the oxide film formed in the air to improve reproducibility. Then the experiments were started for about $10 \mathrm{~min}$ until the steady-state open circuit potential $\left(E_{\text {ocp }}\right)$ was reached. After that the specimen was polarized anodically from $E_{\text {ocp }}$ to a potential of 500 $\mathrm{mV}_{\text {vs.SCE }}$ at a scan rate of $1.667 \mathrm{mV} / \mathrm{s}$. As soon as this potential was reached, it was reversed to $E_{\text {ocp }}$ at the same scanning rate. The peak activation current $\left(I_{\mathrm{a}}\right)$ was measured during the forward scans and the peak reaction current $\left(I_{\mathrm{r}}\right)$ during the backward scans, respectively. The degree of sensitivity of specimens with different heat treatment was measured as the ratio $R_{\mathrm{a}}=I_{\mathrm{r}} / I_{\mathrm{a}}$, and the sensitisation limit value was $1.0 \%$ according to the previous works $[1,17]$. Each test was repeated at least three times in order to assure its repeatability. After DL-EPR measurements, the morphologies of IGC attack were observed by light optical microscopy and SEM using JEOL JSM-6400 Electron Microscope.

\subsection{Oxalic Acid Etch Test}

All specimens were dipped into $10 \%$ oxalic acid solution (100 g oxalic acid crystals dissolved in $900 \mathrm{~mL}$ deionized water) at $1 \mathrm{~A} / \mathrm{cm}^{2}$ for $90 \mathrm{~s}$ according to ASTM A262 Practice A. During the etch test, the specimens were made as anode and a stainless steel sheet with an area $20 \mathrm{~mm} \times 30 \mathrm{~mm}$ was used as cathodic. After the oxalic acid test, etched surfaces were rinsed with deionized water and alcohol and then dried. The microstructures were observed in the SEM, and the etched structures are classified as step, dual and ditch.

\section{Results and Discussion}

\subsection{IGC Resistance of B316LX from DL-EPR Test}

Figure 1 shows the typical DL-EPR curves for specimen after solution and sensitisation heat treatments at different temperatures. During the forward scan, the current density is attributed to the active dissolution of the whole surface, and the maximum of current density $I_{\mathrm{a}}$ is obtained. Then the current density decreases to $1 \times 10^{-4} \mathrm{~A} / \mathrm{cm}^{2}$ before 

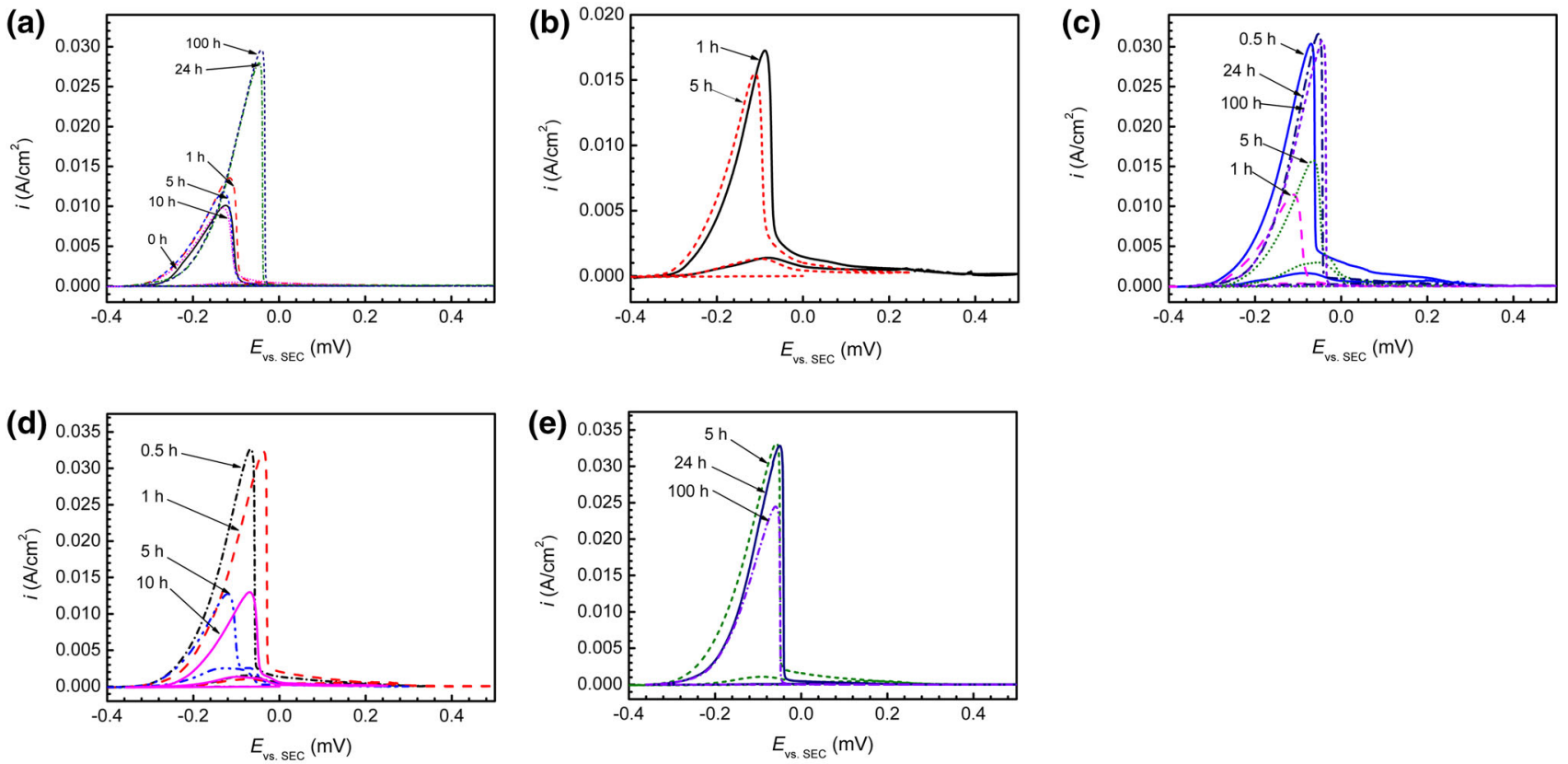

Fig. 1 DL-EPR curves for B316LX after solution and sensitization heat treatment at different temperatures for various time: a $600{ }^{\circ} \mathrm{C}$; b $650{ }^{\circ} \mathrm{C}$; c $700{ }^{\circ} \mathrm{C}$; d $750{ }^{\circ} \mathrm{C}$; e $800{ }^{\circ} \mathrm{C}$

reaching the reverse potential of $500 \mathrm{mV}$, and within this wide passive range from $-1.0 \mathrm{~V}$ to $500 \mathrm{mV}$, a thin passive film mainly composed with chromium and iron oxides can form on the specimen surface. During the reverse scan, the current density is attributed to the active dissolution of chromium depletion zones at grain boundaries due to precipitation of chromium carbides in ASSs [11]. $I_{\mathrm{r}}$ is the maximum of current density in the reverse scan, and then the values of $R_{\mathrm{a}}=I_{\mathrm{a}} / I_{\mathrm{r}}$ can be defined as the degree of sensitisation $[18,19]$.

The variation of the degree of sensitisation of B316LX with aging time and temperature is shown in Table 1. From Fig. 1 and Table 1, it can be found that the variation of $R_{\mathrm{a}}$ shows two tendencies. Firstly, at lower temperature, the specimens need a long sensitisation time to reach the high $R_{\mathrm{a}}$ values, for example, $10 \mathrm{~h}$ to reach $4.86 \%$ at $600{ }^{\circ} \mathrm{C}, 1 \mathrm{~h}$ to reach $5.11 \%$ at $650{ }^{\circ} \mathrm{C}$ and $10 \mathrm{~h}$ to reach $3.48 \%$ at

Table $1 R_{\mathrm{a}}$ values calculated from EPR curves for B316LX ASS

\begin{tabular}{lllllll}
\hline Temperature $\left({ }^{\circ} \mathrm{C}\right)$ & \multicolumn{6}{l}{ Time $(\mathrm{h})$} \\
\cline { 2 - 7 } & 0.5 & \multicolumn{1}{l}{1} & \multicolumn{1}{l}{5} & 10 & 24 & 100 \\
\hline 600 & - & 1.82 & 1.46 & 4.86 & 0.26 & 0.06 \\
650 & - & 5.11 & 8.45 & - & & \\
700 & 5.65 & 9.06 & 18.77 & - & 1.39 & 0.48 \\
750 & 4.85 & 10.18 & 20.18 & 12.82 & & \\
800 & - & - & 3.48 & - & 0.61 & 0.02 \\
\hline
\end{tabular}

$800{ }^{\circ} \mathrm{C}$. However, at the medium temperature, the high $R_{\mathrm{a}}$ values can be obtained in a short sensitisation time, such as $0.5 \mathrm{~h}$ at $700{ }^{\circ} \mathrm{C}$ and $750{ }^{\circ} \mathrm{C}$ to reach 5.65 and $4.85 \%$. Secondly, at every aging temperature, the $R_{\mathrm{a}}$ increases with the aging time (stage I), afterward; however, it decreases after $24 \mathrm{~h}$ (stage II), meaning that the IGC sensitisation of the aged B316LX specimens decreases when the aging time is long enough. This phenomenon can be explained by chromium-depleted theory as follows.

According to chromium-depleted theory, $M_{23} \mathrm{C}_{6}$ carbide precipitates are almost responsible for sensitisation to IGC during sensitisation treatment of ASS [15]. The formation of $M_{23} \mathrm{C}_{6}$ carbide precipitates which nucleate and grow first at the austenite grain boundaries and lead to a lower chromium content in their vicinity creating the well-known chromium-depleted zone. During stage I, the formation of $M_{23} \mathrm{C}_{6}$ is the primary process, but the diffusion of chromium element is not fast enough to prevent formation of the chromium-depleted zones at grain boundaries. The fraction of chromium in the chromium-depleted zones decreases with the aging time, which induces a severe IGC with sensitisation time going [20,21]. During stage II, the formation rate of $M_{23} \mathrm{C}_{6}$ is limited by the low carbon content, and chromium-depleted zones are healed up by the diffusion of chromium from the crystals to the grain boundaries $[22,23]$. The kinetics of this process so-called healing or desensitization depends on the service temperature, carbon content and also on prior deformation [6]. 


\subsection{IGC Resistance of B316LX from Oxalic Acid Etch Test}

The correlation between the $R_{\mathrm{a}}$ values from DL-EPR curves and SEM microstructures after the oxalic acid etch test is shown in Fig. 2. According to ASTM A262, the specimens aged at $750{ }^{\circ} \mathrm{C}$ for $0.5 \mathrm{~h}$ and at $800{ }^{\circ} \mathrm{C}$ for $5 \mathrm{~h}$ do not show intergranular corrosion (IGC). Meanwhile, the specimen aged at $600{ }^{\circ} \mathrm{C}$ for $10 \mathrm{~h}$ exhibits a very slight IGC attack with a step structure, and specimens aged at $650{ }^{\circ} \mathrm{C}$ for $5 \mathrm{~h}$ and at $700{ }^{\circ} \mathrm{C}$ for $1 \mathrm{~h}$ exhibit a dual structure, mixed with step and ditch structures. The specimens aged at $700{ }^{\circ} \mathrm{C}$ for $5 \mathrm{~h}$, at $750{ }^{\circ} \mathrm{C}$ for $1 \mathrm{~h}$ and at $750{ }^{\circ} \mathrm{C}$ for $5 \mathrm{~h}$ are classified as the ditch structure, and all the grains are completely encircled by etched grain boundaries, characteristic of completely sensitized materials. Meanwhile, the degree of IGC for the specimen aged at $750{ }^{\circ} \mathrm{C}$ for $5 \mathrm{~h}$ is obviously more severe than the other two specimens. It can be seen that the values of $R_{\mathrm{a}}$ are in accordance with the results from oxalic acid etch test, where there is no IGC or slight step structure with values of $R_{\mathrm{a}}$ below 5\%; however, there is a severe IGC attack with dual and ditch structures when the values of $R_{\mathrm{a}}$ are above $5 \%$. So the approximate value of $R_{\mathrm{a}}=5 \%$ is assumed to be the upper sensitization limit for the IGC attack.

The IGC sensitisation of B316LX ASS is governed by the growth of chromium-rich carbides at grain boundaries. The precipitation of $M_{23} \mathrm{C}_{6}$ is a diffusion-controlled process and proceeds by nucleation and growth, which are affected by temperature and nature of grain boundaries for a given material. At high temperatures, nucleation of $\mathrm{M}_{23} \mathrm{C}_{6}$ becomes difficult, but the growth is very fast due to the higher diffusion rates of elements. At low temperature the process of nucleation is easy to occur but the growth of
$M_{23} \mathrm{C}_{6}$ is slow due to the lower diffusion rate. So B316LX shows a good IGC resistance at high and low temperatures. However, at the appropriate medium temperature, the processes of nucleation and growth of the $M_{23} \mathrm{C}_{6}$ precipitation both have fast rates to induce a severe IGC.

The correlation between the $R_{\mathrm{a}}$ values from DL-EPR curves and SEM images after oxalic acid etch test for B316LX with long-time sensitization treatment is shown in Fig. 3. It is interesting to note that, at these conditions, there are more attacked holes inside the grains, indicating that fine $M_{23} \mathrm{C}_{6}$ precipitates have formed not only at grain boundaries but also in the grains after long-time sensitization treatment. According to Sahlaoui et al. [20], the chromium carbides precipitation formed by heterogeneous nucleation always starts at grain boundaries (intergranular precipitation), then later spreads to the twin boundaries and finally occurs on the dislocations networks within the grains. All these precipitation sites are easy to be attacked by pitting corrosion and IGC, which is the reason why more pits occur inside grains for specimens aged for $100 \mathrm{~h}$ [24].

In DL-EPR test, the "self-healing" condition was achieved after aging $24 \mathrm{~h}$ according to the low values of $R_{\mathrm{a}}$. However, the microstructures of these specimens continue to be ditch structures with a severe IGC susceptibility after oxalic acid etch test. This is because the healing process in DL-EPR test is based on bulk chromium diffusion to the chromium-depleted regions but not on the dissolution of $M_{23} \mathrm{C}_{6}$ carbides [5]. Since the precipitation of $M_{23} \mathrm{C}_{6}$ carbides is the reason of IGC in oxalic acid etch test, the IGC susceptibility of tin-added ASS increases with aging time. However, the chromium-depleted zone is the main attacked area in the DL-EPR test, so the IGC susceptibility of tin-added ASS shows a decrease tendency
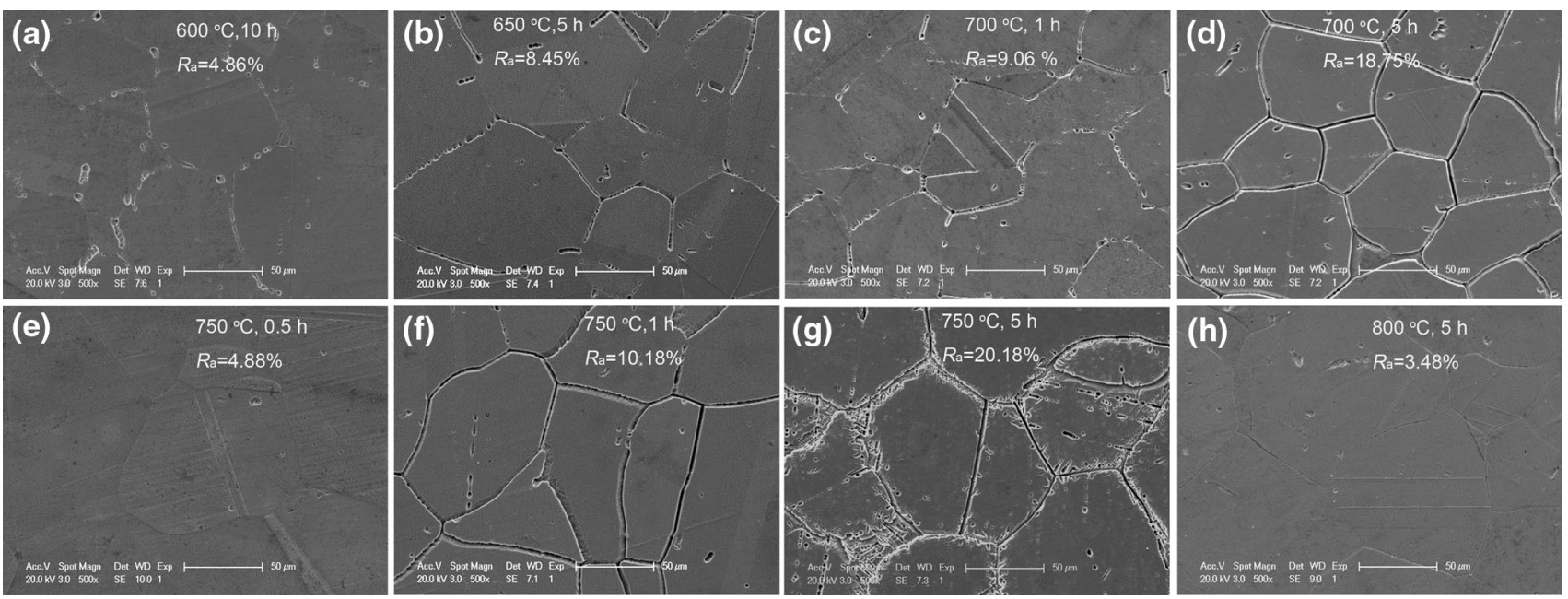

Fig. 2 Morphologies of B316LX with short-time-sensitizing treatment at different temperatures for various time after oxalic acid etch: a $600{ }^{\circ} \mathrm{C}$, $10 \mathrm{~h} ; \mathbf{b} 650{ }^{\circ} \mathrm{C}, 5 \mathrm{~h} ; \mathbf{c} 700{ }^{\circ} \mathrm{C}, 1 \mathrm{~h} ; \mathbf{d} 700{ }^{\circ} \mathrm{C}, 5 \mathrm{~h} ; \mathbf{e} 750{ }^{\circ} \mathrm{C}, 0.5 \mathrm{~h} ; \mathbf{f} 750{ }^{\circ} \mathrm{C}, 1 \mathrm{~h} ; \mathbf{g ~} 750{ }^{\circ} \mathrm{C}, 5 \mathrm{~h} ; \mathbf{h} 800{ }^{\circ} \mathrm{C}, 5 \mathrm{~h}$ 

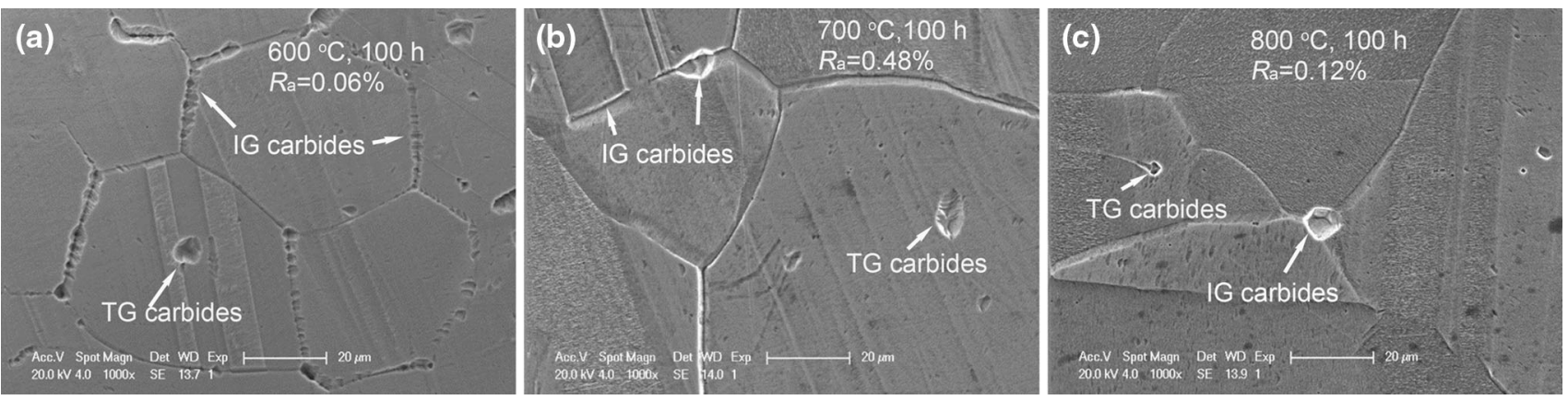

Fig. 3 Morphologies of B316LX with long-time-sensitizing treatment at different temperatures for $100 \mathrm{~h}$ and etching by oxalic acid: a $600{ }^{\circ} \mathrm{C}$; b; $700{ }^{\circ} \mathrm{C} ; \mathbf{c} 800{ }^{\circ} \mathrm{C}$

after aging $24 \mathrm{~h}$ from the DL-EPR results. The results from these two tests are in accordance with each other during the short-time sensitization. However, after long-time sensitisation, the oxalic acid etch test reveals the further precipitation of $M_{23} \mathrm{C}_{6}$ carbides, and the DL-EPR test reveals the self-healing of chromium-depleted regions through chromium diffusion to grain boundaries.

Figure 4 shows the time-temperature-sensitisation (TTS) curves of B316LX ASS derived from $10 \%$ oxalic acid etch test and DL-EPR test with the value of $R_{\mathrm{a}}=5 \%$. The noses of the curves from two tests are located at $750{ }^{\circ} \mathrm{C}$ with an exposure time between $30 \mathrm{~min}$ and $1 \mathrm{~h}$. Within short aging time (less than $24 \mathrm{~h}$ ), the two TTS curves are coincident. However, with higher aging time they split because the result of DL-EPR test shows a recovery phenomenon and the oxalic acid etch test shows a continuous increasing IGC sensitisation. The precipitation curve of $M_{23} \mathrm{C}_{6}$ carbides is also shown in Fig. 4 [18, 25], and it can seen that the precipitation of $M_{23} \mathrm{C}_{6}$ carbides is almost entirely responsible for the IGC sensitisation during aging of ASSs. The nucleation and growth of $M_{23} \mathrm{C}_{6}$

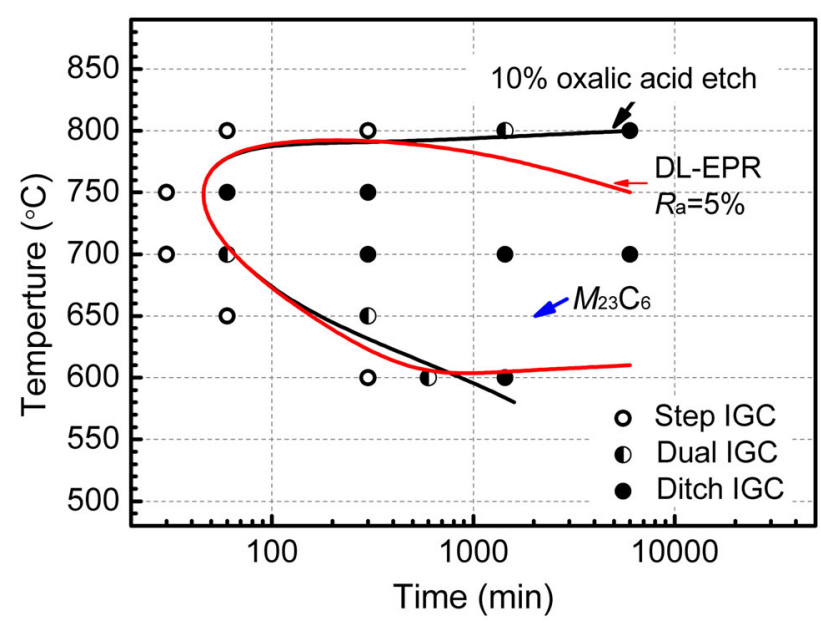

Fig. 4 TTS curves of tin-added ASS derived from 10\% oxalic acid etch test carbides take place at relatively higher temperatures $\left(700-800{ }^{\circ} \mathrm{C}\right)$ as illustrated by Fig. 4 .

\subsection{Evaluation of Chromium Depletion and IGC Sensitization}

Nucleation and growth of new phases such as $M_{23} \mathrm{C}_{6}, \sigma$ and $\eta$ phases cause significant changes in the microstructure of annealed ASSs in the temperature range $600-800{ }^{\circ} \mathrm{C}$. These new phases prefer to nucleate at grain boundaries, dislocation and twin boundaries with high energy [19]. Figure 5 shows a TEM micrograph of $M_{23} \mathrm{C}_{6}$ intergranular precipitates of B316LX ASS sensitized at $750{ }^{\circ} \mathrm{C}$ for $10 \mathrm{~h}$, and the electron diffraction pattern of intergranular precipitates mainly corresponds to chromium carbide with the $M_{23} \mathrm{C}_{6}$ structure, similar to those found in literatures [19]. There are two points $\mathrm{A}$ and $\mathrm{B}$ representing the $M_{23} \mathrm{C}_{6}$ and the chromium-depleted zone, respectively, in Fig. 5, and the chemical composition at point $\mathrm{A}$ and $\mathrm{B}$ are examined by EDS. The EDS results of $M_{23} \mathrm{C}_{6}$ carbides shows significantly high contents of chromium $(63.8 \mathrm{wt} \%)$ and molybdenum (10.5 wt $\%$ ), but relatively low contents of

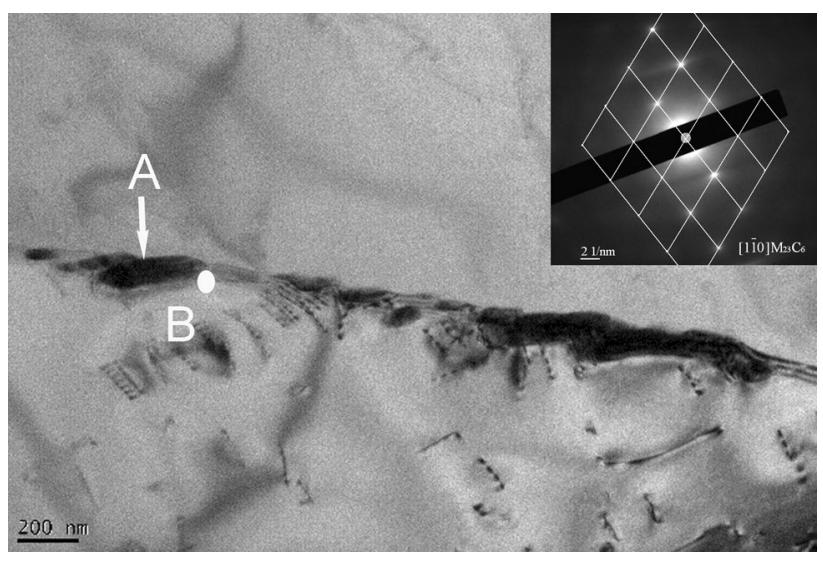

Fig. 5 TEM micrograph and electron diffraction pattern of $M_{23} \mathrm{C}_{6}$ intergranular precipitates in B316LX ASS sensitized at $750{ }^{\circ} \mathrm{C}$ for $10 \mathrm{~h}[19]$ 
nickel (2.6 wt\%) and iron (16.3 wt\%). However, the content of chromium $(11.6 \mathrm{wt} \%)$ is lower at point $\mathrm{B}$, which means that the chromium-depleted zone has been formed beside the carbide $M_{23} \mathrm{C}_{6}$ precipitate. So the transmission electron diffraction (TED) and EDS analysis corroborate the formation of chromium-depleted zone around $M_{23} \mathrm{C}_{6}$ precipitates at grain boundaries. The nucleation and growth of chromium-rich phases and mainly $M_{23} \mathrm{C}_{6}$ carbides affect the distribution of metallic elements at local area appreciably, such as chromium, molybdenum and iron near matrix-carbides interfaces at grain boundaries, and then the aged materials present a high grade of sensitization along with increased formation of $M_{23} \mathrm{C}_{6}$ carbides.

From the EDS result, the chromium level decreases from $16.14 \mathrm{wt} \%$ at the substrate to $11.6 \mathrm{wt} \%$ at aging temperature of $750{ }^{\circ} \mathrm{C}$ for $10 \mathrm{~h}$. According to Jain et al. [26], if the local chromium content drops below $12 \mathrm{wt} \%$, the chromium-depleted zones become prone to localized pit corrosion or IGC in chloride and severe corrosive environments. So the recovery of chromium content at grain boundaries to reach the critical value of $12 \mathrm{wt} \%$ is sufficient to produce self-healing and prevent IGC attack. With the aging time prolonging to $100 \mathrm{~h}$, the chromium level returns to original content because of the chromium diffusion from the matrix to the carbide-matrix interfaces to prevent formation of the chromium-depleted zones at grain boundaries.

More precipitations such as $M_{6} \mathrm{C}$ and the sigma, chi and Laves intermetallic phases might occur with long-time sensitization [27-29]. Figure 6 shows the TEM micrograph and electron diffraction pattern of the discrete precipitates of Laves phase $\left(A B_{2}\right)$ inside the grains of B316LX sensitized at $750{ }^{\circ} \mathrm{C}$ for $100 \mathrm{~h}$. The Laves precipitation in austenite has a very slow kinetics. These precipitates are with a flake-like morphology or as discrete and have mean contents of $49 \mathrm{wt} \%$ Mo and 17\% Cr according to EDS

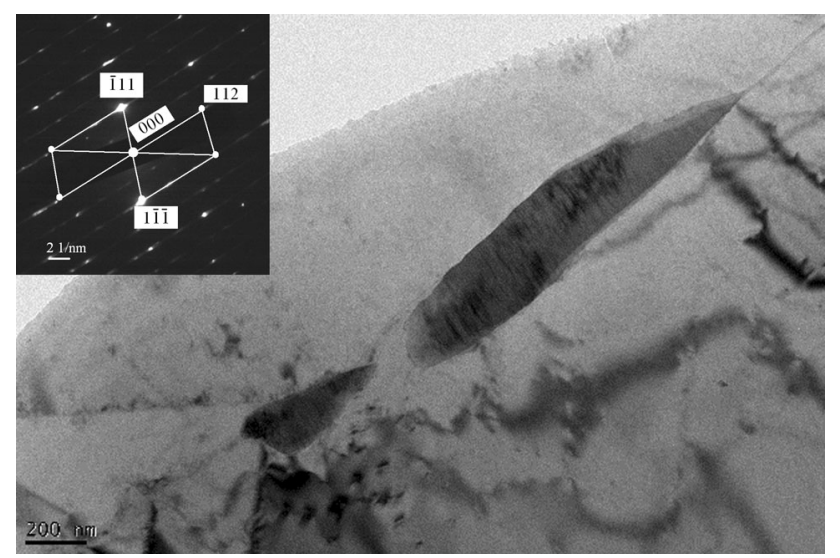

Fig. 6 TEM micrograph and electron diffraction pattern of precipitation in B316LX ASS sensitized at $750{ }^{\circ} \mathrm{C}$ for $100 \mathrm{~h}$

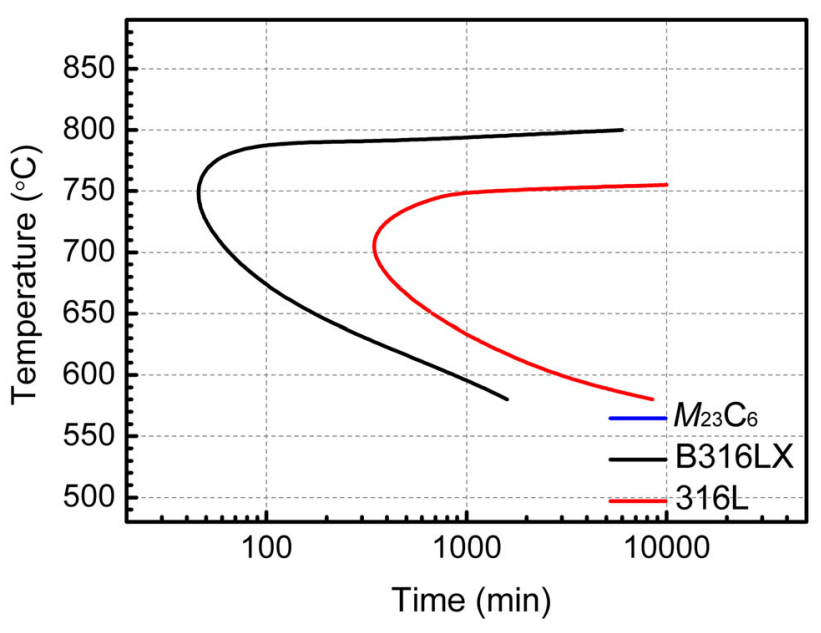

Fig. 7 TTS curves of B316LX and 316L steels derived from $10 \%$ oxalic acid etch test

result; therefore, its precipitation causes the impoverishment of these elements in the adjacent matrix, so it is the reason that more pits occur in the grains with aging time. The Laves phases also precipitate along the grain boundaries and induce IGC.

\subsection{Effect of Tin on IGC}

Figure 7 shows the TTS curves of B316LX and 316L steels derived from $10 \%$ oxalic acid etch test. It can be seen that the TTS curve of B316LX steel with tin addition shifts to the top-left direction, meaning a higher nose temperature and a shorter aging time compared with $316 \mathrm{~L}$ steel. From this result, it can be deduced that tin element increases the IGC susceptibility of ASSs. The solid solubility of tin in austenite is limited due to the big atomic radius of tin atoms, and then tin atoms tend to diffuse toward the grain boundaries, maybe inducing a more IGC susceptibility. However, it is difficult to find tin element at grain boundaries because of the low content of tin $(0.08 \mathrm{wt} \%)$ by SEM, TEM and XPS techniques, so more tests need to be done in order to analyze the effect of tin on IGC of ASSs.

\section{Conclusions}

1. IGC resistance of tin-added B316LX ASS can be strongly affected by microstructural changes induced by sensitizing treatments. The $M_{23} \mathrm{C}_{6}$ carbide and intermetallic Laves phase are the principal precipitates formed in $\mathrm{B} 316 \mathrm{LX}$. The precipitation of $M_{23} \mathrm{C}_{6}$ can cause chromium depletion zone at grain boundaries and increase the IGC susceptibility of this steel. 
2. DL-EPR test is unsuitable to evaluate the IGC susceptibility of ASSs with long-time sensitization. The chromium depletion zone can be healed up after long aged; however, more carbides and intermetallic phases continue to form at grain boundaries and inside the grains, and induce more severe IGC susceptibility and pits attacks.

3. Tin addition increases the IGC susceptibility of ASSs, maybe it is caused by the diffusion of tin element toward the grain boundaries because of larger atomic radius, and however, further work needs be done to analyze this phenomenon.

Acknowledgments This work was financially supported by the National Natural Science Foundation of China (Nos. 51501041, 51131008 and 51371053), China Postdoctoral Science Foundation (No. 2013M541463), National Key Technology R\&D Program (No. 2012BAE04B00), and Doctoral Fund of Ministry of Education of China (No. 20120071110013).

\section{References}

[1] A. Pardo, M.C. Merino, A.E. Coy, F. Viejo, M. Carboneras, R. Arrabal, Acta Mater. 55, 2239 (2007)

[2] F.L. Sun, X.G. Li, X.Q. Cheng, Acta Metall. Sin. (Engl. Lett.) 28, 115 (2015)

[3] J. Degerbeck, Mater. Corros. 29, 179 (1978)

[4] L.L. Machuca, L. Murray, R. Gubner, S.I. Bailey, Mater. Corros. 65, 8 (2014)

[5] A. Pardo, M.C. Merino, M. Carboneras, F. Viejo, R. Arrabal, J. Muñoz, Corros. Sci. 48, 1075 (2006)

[6] A.Y. Kina, V.M. Souza, S.S.M. Tavares, J.M. Pardal, J.A. Souza, Mater. Charact. 59, 651 (2008)

[7] X.F. Yu, S.H. Chen, Y. Liu, F.F. Ren, Corros. Sci. 52, 1939 (2010)
[8] M.G. Pujar, N. Parvathavarthini, R.K. Dayal, S. Thirunavukkarasu, Corros. Sci. 51, 1707 (2009)

[9] R. Singh, B. Ravikumar, A. Kumar, P.K. Dey, I. Chattoraj, Metall. Mater. Trans. A 34, 2441 (2003)

[10] V. Moura, A.Y. Kina, S.S.M. Tavares, L.D. Lima, F.B. Mainier, J. Mater. Sci. 43, 536 (2008)

[11] C.T. Kwok, K.H. Lo, W.K. Chan, F.T. Cheng, H.C. Man, Corros. Sci. 53, 1581 (2011)

[12] N.D. Nam, M.J. Kim, Y.W. Jang, J.G. Kim, Corros. Sci. 52(14), 14 (2010)

[13] K. Osozawa, Boshoku Gijutsu 20, 120 (1971)

[14] K. Osozawa, Y. Fukasc, K. Yokota, Boshoku Gijutsu 20, 69 (1971)

[15] Y. Xuan, C. Zhang, N.Q. Fan, Z.G. Yang, Acta Metall. Sin. (Engl. Lett.) 27, 539 (2014)

[16] ASTM International, US Patent G108-2010. July 2005

[17] D.N. Wasnik, V. Kain, I. Samajdar, B. Verlinden, P.K. De, Acta Mater. 50, 4587 (2002)

[18] J. Gong, Y.M. Jiang, B. Deng, J.L. Xu, J.P. Hu, J. Li, Electrochim. Acta 55, 5077 (2010)

[19] A.P. Majidi, M.A. Streicher, Corrosion 40, 584 (1984)

[20] H. Sahlaoui, K. Makhlouf, H. Sidhom, J. Philibert, Mater. Sci. Eng., A 372, 98 (2004)

[21] Y.F. Yin, R.G. Faulkner, Corros. Sci. 49, 2177 (2007)

[22] C. Zhong, M.F. He, L. Liu, Y.T. Wu, Y.J. Chen, Y.D. Deng, B. Shen, W.B. Hu, J. Alloys Compd. 504, 377 (2010)

[23] G.H. Aydoğdu, M.K. Aydinol, Corros. Sci. 48, 3565 (2006)

[24] W.M. Tian, Y.J. Ai, S.M. Li, N. Du, C. Ye, Acta Metall. Sin. (Engl. Lett.) 28, 449 (2015)

[25] C.W. Kovach, High Performance Stainless Steels, in Reference Book Series No. 11021 (Nickel Development Institute Toronto, Canada, 2000), pp. 16-17

[26] S. Jain, N.D. Budiansky, J.L. Hudson, J.R. Scully, Corros. Sci. 52, $873(2010)$

[27] K. Guan, X.D. Xu, H. Xu, Z.W. Wang, Nucl. Eng. Des. 235, $2485(2005)$

[28] C. Zhong, F. Liu, Y.T. Wu, J.J. Le, L. Liu, M.F. He, J.C. Zhu, W.B. Hu, J. Alloys Compd. 520, 11 (2012)

[29] M. Matula, L. Hyspecka, M. Svoboda, V. Vodarek, C. Dagbert, J. Galland, Z. Stonawska, L. Tuma, Mater. Charact. 46, 203 (2001) 